\title{
PLANEJAMENTO DE ESPAÇOS VERDES PARA MINIMIZAÇÃO DO ESCOAMENTO SUPERFICIAL DAS ÁGUAS PLUVIAIS
}

\author{
GREEN SPACES PLANNING FOR REDUCTION OF SURFACE \\ RAINWATER DRAINAGE
}

\begin{abstract}
Marcela Minatel Locatelli
Engenheira Florestal, Mestranda em Recursos Florestais na Escola Superior de Agricultura "Luiz de Queiroz" da Universidade de São Paulo, Piracicaba, SP.

marcelalocatelli@usp.br

Patrícia Mara Sanches

Arquiteta e Urbanista, Mestre em Arquitetura e Urbanismo, Doutoranda em Recursos Florestais na Escola Superior de Agricultura "Luiz de Queiroz" da Universidade de São Paulo, Piracicaba, SP. patricia.msanches@usp.br

Jefferson Lordello Polizel

Doutor em Geografia Física pela Universidade de São Paulo, Técnico em Informática do Laboratório de Métodos Quantitativos, ESALQ/USP.

jlpolize@usp.br

Demóstenes Ferreira da Silva Filho

Engenheiro Agrônomo, Professor Livre docente da Escola Superior de Agricultura "Luiz de Queiroz" da Universidade de São Paulo, Piracicaba, SP.

dfilho@usp.br
\end{abstract}

\section{RESUMO}

Dentre os diversos serviços ambientais fornecidos pelas áreas verdes urbanas, podemos destacar o aumento da permeabilidade do solo e interceptação da água da chuva, principalmente pelas copas das árvores. Dessa forma, reduzem a quantidade e a velocidade do escoamento superficial da água da chuva, e, consequentemente os riscos de alagamentos e a sobrecarga nos sistemas de drenagem. Este trabalho teve por objetivo a identificação de áreas prioritárias para implantação de espaços verdes na cidade de São Paulo, visando a diminuição do escoamento superficial das águas pluviais e minimização das enchentes a jusante. As condicionantes que auxiliaram nesta priorização foram a quantidade de vegetação, expressa pelo mapa de TVI (Transformed Vegetation Index), e a topografia, processadas em ambiente SIG 
(Sistemas de Informações Geográficas). Os dados obtidos foram sintetizados em um mapa que aponta as áreas prioritárias para arborização urbana. Os resultados mostram duas grandes manchas formadas por áreas prioritárias para arborização urbana, concentradas nas regiões centro-norte e centro-sul da área de estudo. Essas manchas devem receber maior atenção quanto à implementação de espaços verdes, principalmente através da arborização viária. Esses espaços verdes poderão conectar grandes fragmentos de vegetação da cidade.

Palavras-chave: Arborização urbana; Sensoriamento remoto; Planejamento Urbano; Índice de vegetação; Escoamento superficial

\section{ABSTRACT}

Among several environmental services provided by urban green areas, it can be highlighted the increase of soil permeability and interception of rainwater, mainly through the treetops. Therefore, it is reduced the quantity and speed of surface rainwater drainage, and, consequently, the risks of flooding and drainage systems overloading. The objective of this study is to identify priority areas for the implantation of green spaces in São Paulo City, aiming to reduce the surface rainwater drainage and minimize flooding downstream. The conditions that supported this prioritization were the amount of vegetation, expressed by the TVI (Transformed Vegetation Index) map and the topography, processed in a Geographic Information Systems (GIS) environment. The obtained data were summarized in a map that indicates the priority areas for urban afforestation. The results show two large spots formed by priority areas for urban afforestation, concentrated in the north-central and south-central regions of the focused area. These spots should receive special attention regarding the implementation of green spaces, mainly through the road afforestation. These green spaces may connect large fragments of vegetation in the city.

Keywords: Urban Forestation; Remote Sensing; Urban Planning; Vegetation Index; Surface Drainage. 


\section{INTRODUÇÃO}

Na cidade de São Paulo, assim como no contexto metropolitano brasileiro, os problemas ambientais têm aumentado consideravelmente, resultando na diminuição da qualidade de vida da população. O quadro se revela em um aumento desmensurado de enchentes e ilhas de calor, dificuldades na gestão dos resíduos sólidos, impactos cada vez maiores da utilização de automóvel, e da degradação dos recursos hídricos (JACOBI, 2006).

A presença de espaços verdes no ambiente urbano é um fator essencial no resgate dos aspectos positivos da relação das formas urbanas com a natureza e na amenização de diversos dos problemas citados (JESUS; BRAGA, 2005).

Espaço verde urbano corresponde a toda e qualquer área que contenha vegetação situada em solo permeável ou impermeável na cidade, podendo ser de uso público ou privado (HIJIOKA et al., 2007). Apesar de todos os serviços ambientais amplamente conhecidos oferecidos pelos espaços verdes - conforto térmico, controle da umidade, sombreamento, retenção de poluentes, redução de ruídos, manutenção da biodiversidade, aumento da permeabilidade do solo, controle de processos erosivos e contenção de encostas, efeitos paisagísticos e estéticos (MAGALHÃES, 2013) - o enfoque deste trabalho é direcionado à importância desses espaços para o regime hídrico urbano.

Sabe-se que os espaços verdes aumentam a permeabilidade do solo e interceptam a água da chuva, principalmente pelas copas das árvores. Dessa forma, reduzem a poluição, a quantidade e a velocidade do escoamento superficial da água, e retardam o pico de vazão (ALVES, 2015), diminuindo os riscos de alagamentos e a sobrecarga nos sistemas de drenagem. Estudos desenvolvidos por Silva et al. (2009) demonstram que as espécies arbóreas sibipiruna (Caesalpinia pluviosa) e tipuana (Tipuana tipu) podem interceptar em até $60 \%$ a precipitação que incide sobre suas copas.

Segundo Duarte e Serra (2003), tão importante quanto a disponibilidade de espaços verdes, são sua distribuição e qualidade, uma vez que estes fatores influenciam diretamente nas funções desempenhadas por esses espaços.

Dentre as possibilidades para ampliação dos espaços verdes em áreas densamente edificadas destaca-se o uso da arborização viária para criação de corredores verdes (MAGALHÃES, 2013). 
As geotecnologias, especialmente as técnicas de sensoriamento remoto e geoprocessamento, são muito utilizadas para a quantificação e qualificação da cobertura arbórea urbana, uma vez que constituem um método eficiente e econômico, e possibilitam avaliações periódicas das áreas de interesse (SILVA FILHO, 2004; COSTA, 2010).

Diversos estudos utilizaram geotecnologia para avaliação e planejamento dos espaços verdes urbanos. Podemos citar os trabalhos de Torres (2003) em Viçosa, MG; Bargos e Matias (2012) em Paulínia, SP; Magalhães (2013) em Belo Horizonte, MG e Costa (2010) em São Paulo, SP. Esses estudos utilizam diferentes abordagens para a definição de áreas prioritárias para implementação de espaços verdes: hidrografia, renda da população, relevo, permeabilidade do solo, conectividade da paisagem, dentre outros.

O trabalho de Costa (2010) utiliza critérios para amenização dos riscos de alagamentos na cidade, e constitui uma referência conceitual e metodológica para a área do presente estudo, tendo em vista os problemas apresentados.

Diante do exposto, o presente trabalho teve por objetivo a identificação de áreas prioritárias para implementação de espaços verdes na cidade de São Paulo, tendo como premissa a redução do escoamento superficial das águas pluviais, e visando a minimização de enchentes a jusante.

\section{METODOLOGIA}

\section{ÁREA DE ESTUDO}

O município de São Paulo ( $23^{0} 32.0^{\prime} \mathrm{S}, 46^{0} 37.0^{\prime} \mathrm{W}$ ) possui $1.521 \mathrm{Km}^{2}$ de extensão e concentra 11.253.503 habitantes (IBGE, 2010). O clima é classificado como subtropical (Cwa), segundo Köppen (1948), com temperatura média anual de $19^{\circ} \mathrm{C}$, e precipitação média anual de $1207 \mathrm{~mm}$.

A área do município engloba diversas fitofisionomias da Mata Atlântica, como a Floresta Ombrófila Densa, Floresta Ombrófila Montana e a Mata Nebular; além de campos naturais e formações de várzea. 


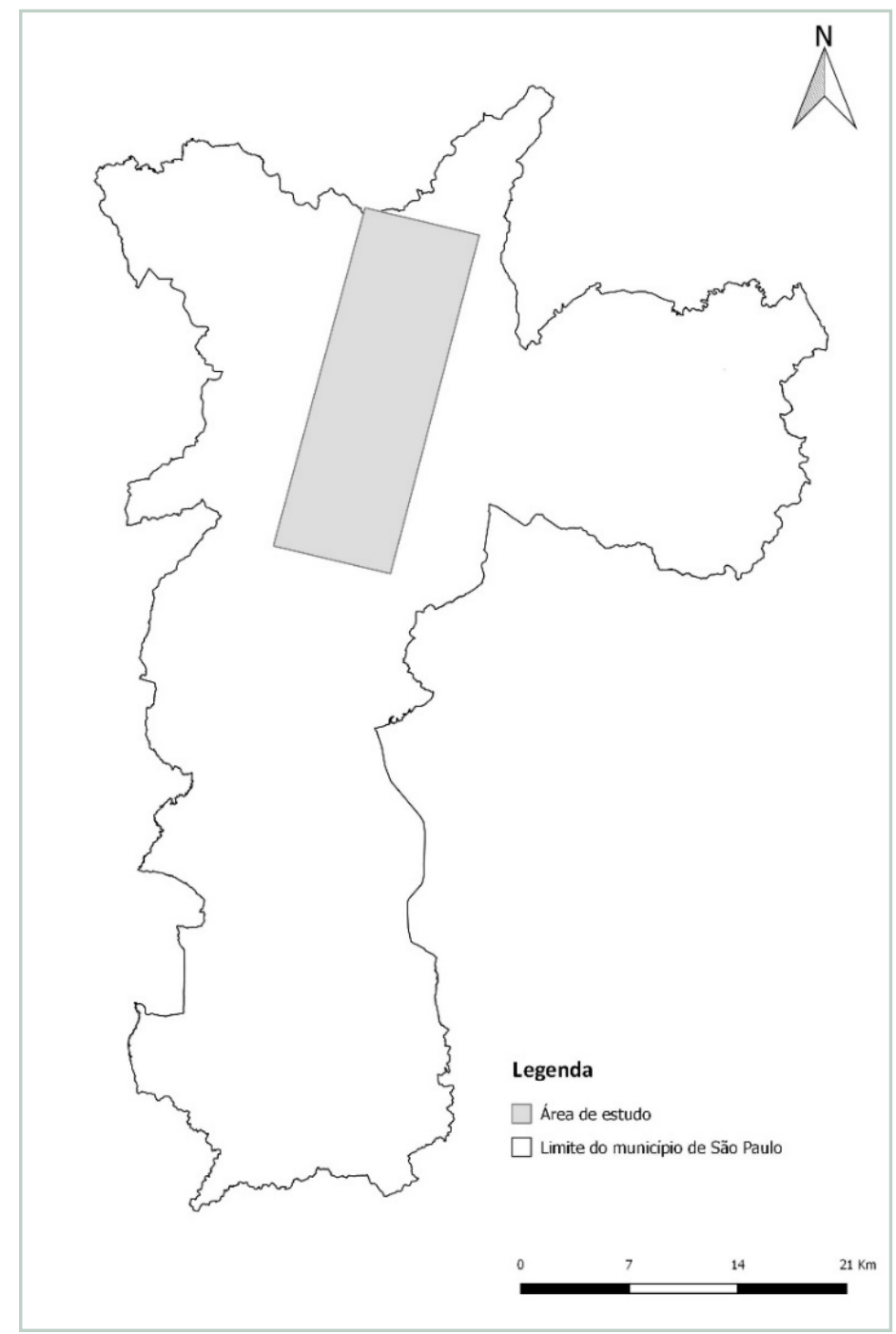

A área do presente estudo corresponde a um retângulo de $5 \times 20 \mathrm{Km}$ do município de São Paulo, que vai do cume da serra da Cantareira ao rio Pinheiros (figura 1) e que corresponde ao objeto de estudo do Projeto de Pesquisa "Infraestrutura verde para a resiliência urbana às mudanças climáticas da cidade de São Paulo" financiado pela FAPESP - Fundação de Amparo à Pesquisa no Estado de São Paulo ${ }^{1}$

Figura 1 - Área de estudo. Fonte: elaborado pelos autores (2017).

Para o desenvolvimento do trabalho foram utilizados Sistemas de Informações Geográficas e imagens do Satélite Wordview 2 do ano de 2016 com resolução de dois metros, cedidas pela Fundação DigitalGlobe.

Foram geradas e analisadas informações de declividade e índice de vegetação (TVI). O objetivo deste estudo foi identificar as áreas de maior declividade e com vegetação insuficiente, áreas estas indicadas para uma política de arborização urbana.

\footnotetext{
${ }^{1}$ Projeto em andamento e financiado pela FAPESP na modalidade Auxílio à Pesquisa - Programa de Pesquisa sobre Mudanças Climáticas Globais - Regular, cujo Processo é 15/10597-0.
} 
O TVI (Transformed Vegetation Index) é um índice de vegetação derivado de imagens multiespectrais, que utiliza as bandas do vermelho e do infravermelho próximo para destacar as áreas vegetadas de uma imagem, e é obtido pela fórmula:

$$
\mathrm{TVI}=\sqrt{100[(I R-R E D)]+[(I R+R E D)]}
$$

Em que: TVI é o índice de vegetação; IR = banda do infravermelho e; RED = banda do vermelho

O mapa de TVI foi gerado no programa QuantumGIS2.14.3, onde foi também reclassificado em quatro classes, sendo que para cada faixa do TVI foi atribuída uma nota (de 0 a 3 ).

Para o mapa de declividade foi utilizado o Modelo Digital de Elevação do Terreno (MDT) da região. Com base no MDT, foi gerado um mapa hipsométrico, conhecido como TIN (Triangulated Irregular Network), e, partir deste, foi obtido o mapa de declividade da área de estudo. Este foi também reclassificado em quatro classes, conforme a tabela 1.

Tabela 1 - Faixas de declividade da área de estu

\begin{tabular}{cc}
\hline Faixas de Declividade (\%) & Reclassificação \\
\hline $0-5$ & 0 \\
$5-10$ & 1 \\
$10-25$ & 2 \\
$25-50$ & 3 \\
\hline
\end{tabular}

Com os dados obtidos realizamos uma álgebra de mapas no programa QuantumGIS2.14.3, subtraindo os valores de TVI pelos valores de declividade. O resultado gerado compreende uma nova imagem, cujos valores de pixels variam de -3 a 3 , correlacionados à prioridade muito alta e prioridade muito baixa para arborização, respectivamente (tabela 2). Dessa foram, obtivemos o mapa que aponta as áreas prioritárias para arborização urbana em função das variáveis mencionadas, conforme metodologia de Costa (2010). 
Tabela 2 - Classes de prioridade para arborização urbana, adaptado de Costa (2010).

\begin{tabular}{cc}
\hline Valores & Reclassificação \\
\hline-3 & Muito Alta \\
-2 & Alta \\
-1 & Média Alta \\
\hline 0 & Média \\
1 & Média Baixa \\
2 & Baixa \\
\hline 3 & Muito Baixa \\
\hline
\end{tabular}

\section{RESULTADOS E DISCUSSÃO}

\section{ÍNDICE DE VEGETAÇÃO (TVI)}

Os resultados obtidos para o TVI são apresentados na figura 2 (a), em que as áreas mais claras correspondem às áreas vegetadas, enquanto que as áreas escuras correspondem às áreas com ausência de vegetação.

A figura 2 (b) contém os resultados da reclassificação da imagem, em que os valores variam de 0 a 3 , sendo que o valor 0 representa áreas com ausência de vegetação (verde claro), valores 1 e 2 (verde médio) representa áreas compostas, predominantemente, por vegetação rasteira, e o valor 4 representa as áreas densamente arborizadas (verde escuro). 

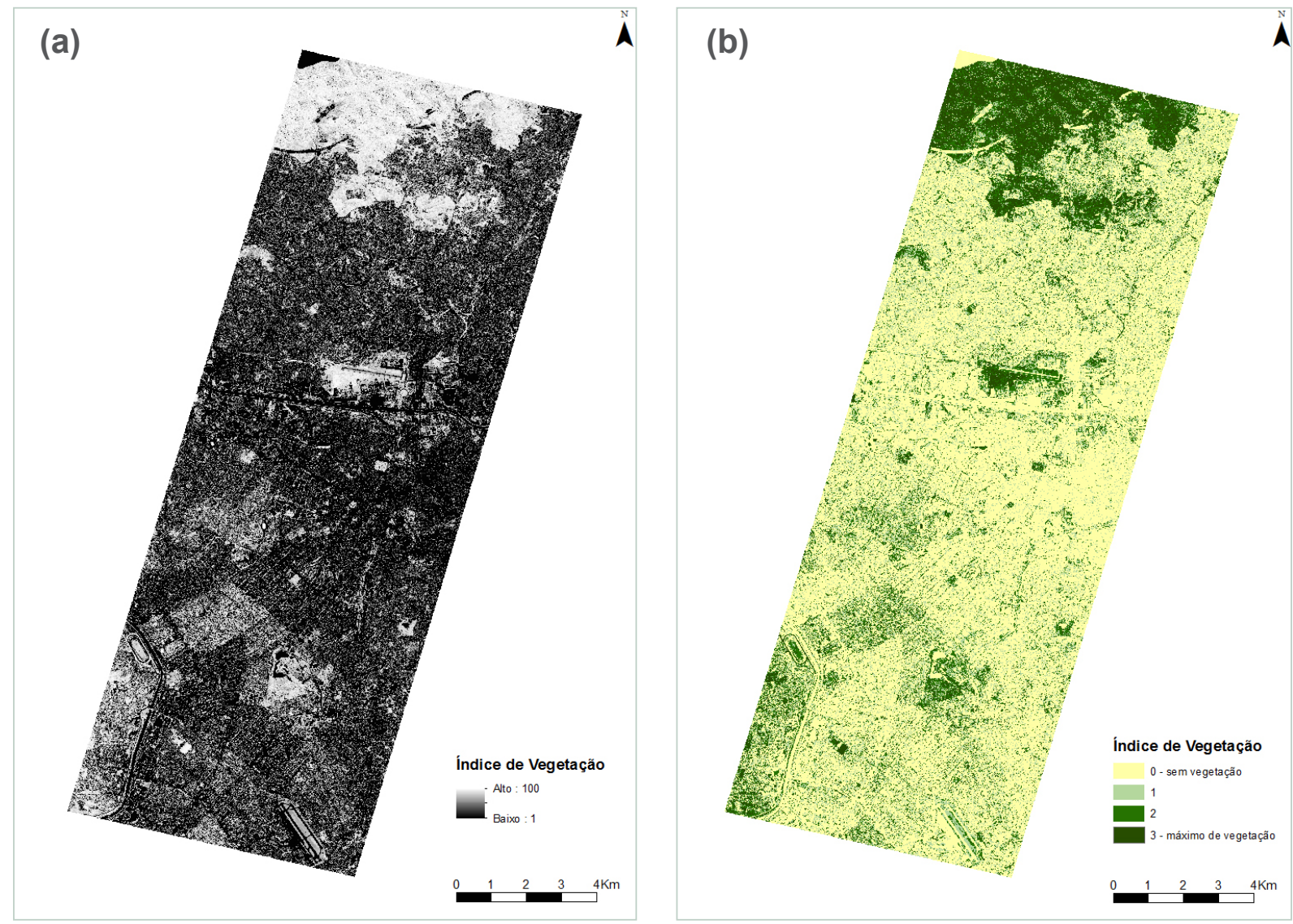

Figura 2 - (a) Índice de vegetação (TVI) da área de estudo; (b) Índice de vegetação (TVI) reclassificado em quatro classes da área de estudo, em que o valor 0 corresponde à ausência de vegetação; 1 e 2 a quantidades intermediárias e; 3 ao máximo de vegetação. Fonte: elaborado pelos autores (2017).

A figura 2(a) apresenta os valores de TVI na forma de gradiente, enquanto a figura 2(b) apresenta os resultados de TVI como valores únicos. A transformação destes valores é essencial para a realização da álgebra de mapas (citada abaixo).

Através da aplicação do TVI foi possível destacar as áreas densamente vegetadas, em contraposição àquelas áreas com ausência de vegetação. A eficiência do TVI foi comprovada por Costa (2010) para qualificação da cobertura arbórea de três subprefeituras de São Paulo, SP.

Podemos verificar que as áreas com máximo índice de vegetação correspondem a parques importantes da cidade de São Paulo, como o Parque Estadual da Cantareira, o Parque Ibirapuera, o Parque da Água Branca e o Parque Trianon, dentre outros. Esse resultado é encontrado também para bairros de classe alta da região, que são mais arborizados que os centros comerciais e os bairros de classe média-baixa. 


\section{DECLIVIDADE}

Os espaços verdes fornecem diversos benefícios às cidades, como a redução do escoamento superficial da água, aumento da permeabilidade e contenção do solo.

A partir do estudo da declividade em áreas urbanas é possível indicar as áreas favoráveis à ocupação humana, e as áreas onde esta deve ser realizada com maior prudência. Áreas declivosas são mais suscetíveis a processos erosivos e altas taxas de escorrimento superficial, e, portanto, devem receber atenção especial quanto à presença de vegetação.

A Lei $n^{\circ} 6.766$ de 1979, que dispõe sobre o parcelamento do solo urbano, em seu artigo terceiro, parágrafo único, inciso III proíbe a construção em terrenos com declividade igual ou superior a $30 \%$. Acima deste limiar, o risco de processos erosivos e deslizamentos de solo é muito elevado.

As áreas mais favoráveis à ocupação humana possuem declividade abaixo de $18 \%$. Os valores intermediários de declividade (de 18 a 30\%) correspondem a áreas onde o processo de ocupação deve ser realizado com prudência, favorecendo usos que mantenham a permeabilidade do solo (TORRES, 2003).

Em estudo sobre o macroplanejamento de áreas verdes urbanas, Torres (2003) discutiu diversos critérios a serem considerados para a distribuição adequada desses espaços. Dentre eles, considerou a declividade como critério extremamente relevante, uma vez que esta pode influenciar o regime hídrico do solo, causando, por exemplo, assoreamento dos rios.

A figura 3(a) apresenta o mapa de declividade da área de estudo, em porcentagem. Já a figura 3(b) contém o mapa de declividade reclassificado em quatro classes, em que o valor 0 representa as áreas de menor declividade, e o valor 3 as áreas de maior declividade. 

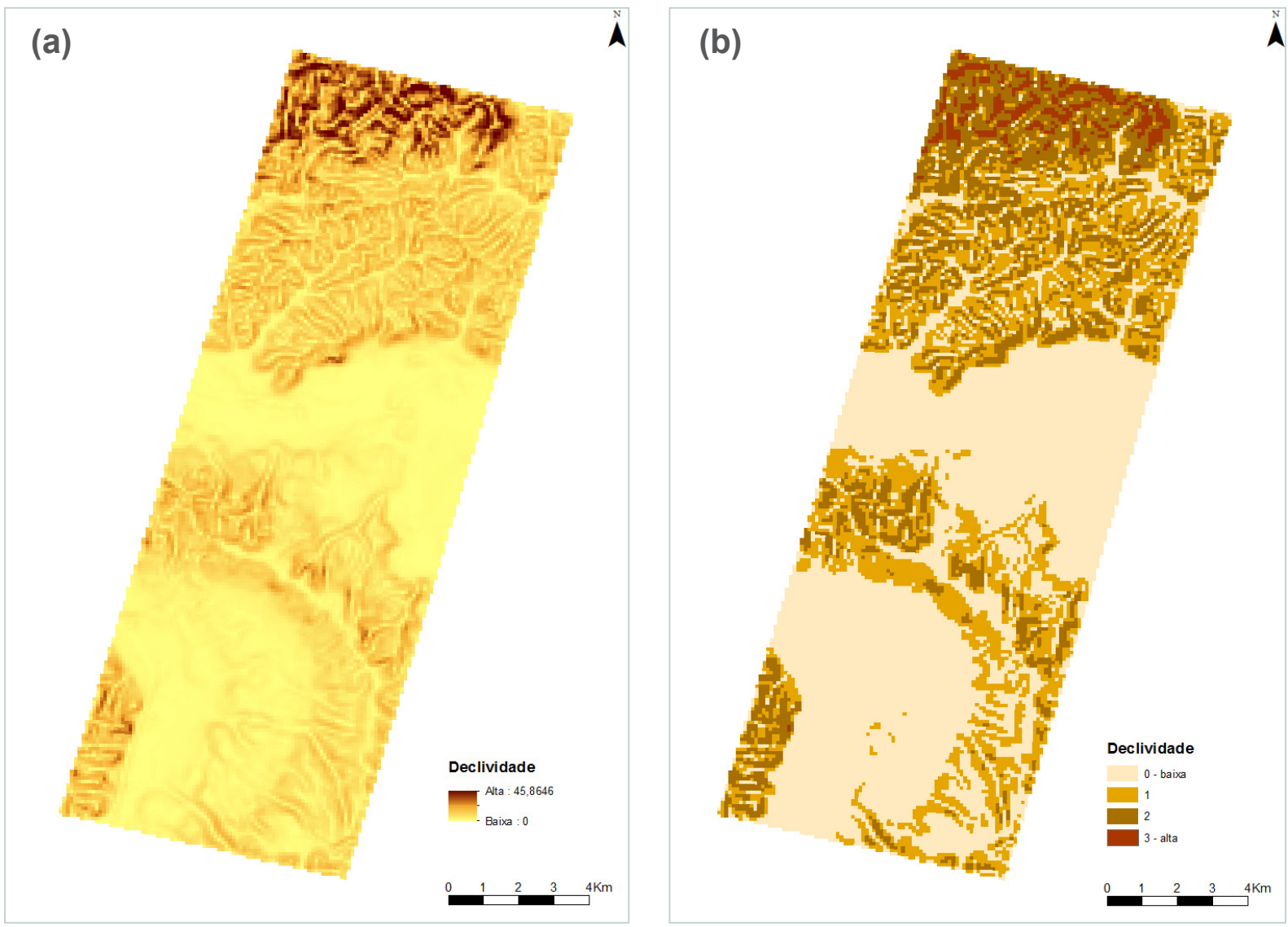

Figura 3 - Declividade da área de estudo: (a) em porcentagem; (b) reclassificada em quatro classes, em que o valor 0 corresponde à menor declividade e; o valor 3 corresponde à declividade máxima. Fonte: elaborado pelos autores (2017).

As figuras acima apresentam características semelhantes às demonstradas para o TVI. A figura 3(a) apresenta os valores de declividade na forma de gradiente, enquanto a figura 3(b) apresenta os resultados como valores únicos. A transformação destes valores é essencial para a realização da álgebra de mapas (citada abaixo).

\section{ÁREAS PRIORITÁRIAS PARA ARBORIZAÇÃO URBANA}

Diversos critérios podem ser analisados durante o planejamento de espaços verdes, como: densidade populacional, índice de áreas verdes e porcentagem de áreas verdes (OLIVEIRA, 1996); declividade e índice de vegetação (COSTA, 2010), hidrografia, tipos de solo, orientação solar, declividade, disposição e abundância de áreas verdes e renda média da população (TORRES, 2003), dentre outros. Neste trabalho analisamos os fatores declividade e índice de vegetação, devido à influência que estes crité- 
rios exercem sobre o escoamento superficial da água da chuva, e consequentemente, sobre os alagamentos urbanos, considerado problema grave na área de estudo.

O resultado da álgebra dos mapas de índice de vegetação (TVI) e declividade, apresentado na figura 4, mostra as prioridades para arborização em sete classes para os distritos presentes na área de estudo.

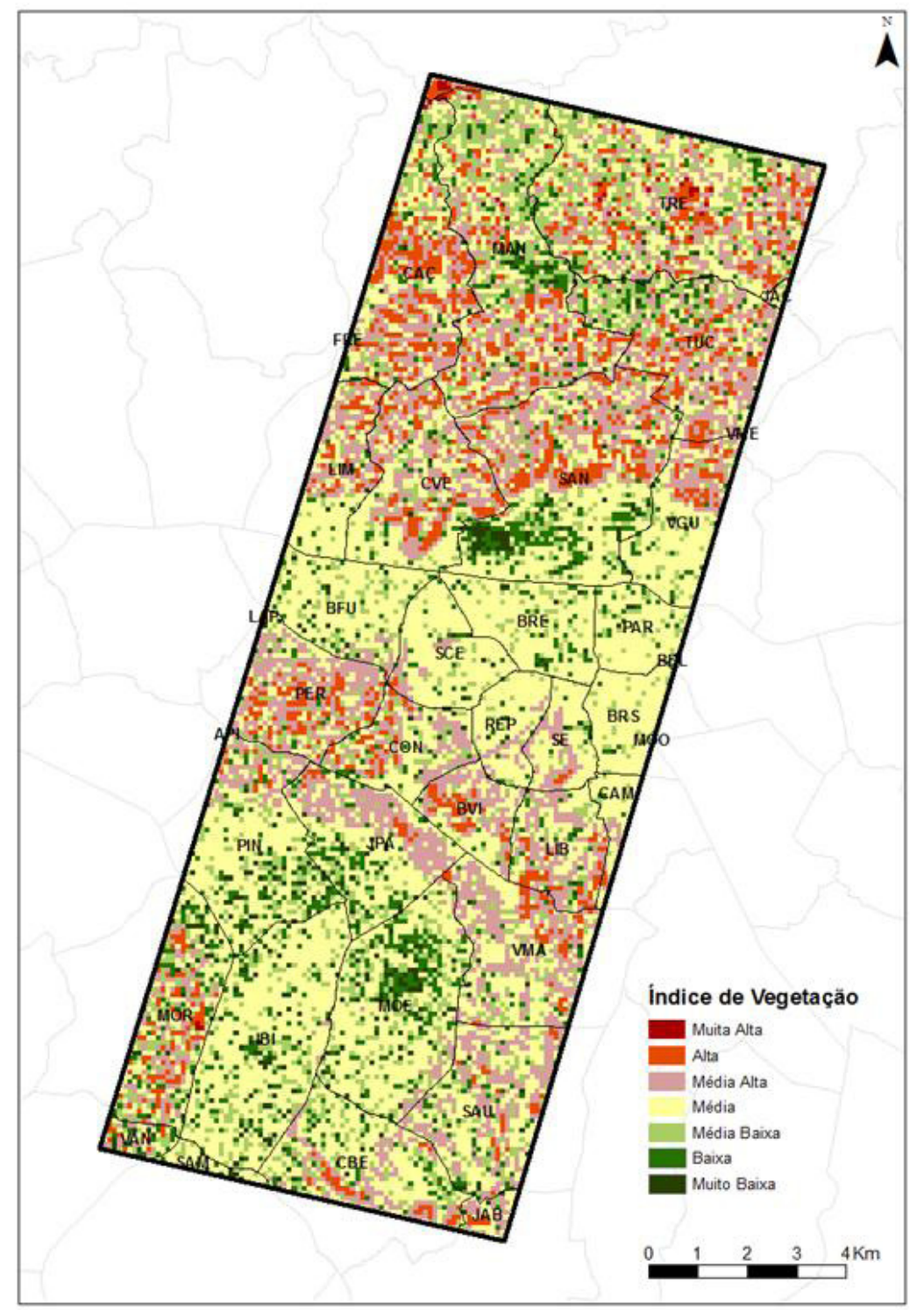

Figura 4 - Regiões prioritárias para arborização urbana nos distritos presentes na área de estudo. Fonte: elaborado pelos autores (2017). Em que:

MAN: Mandaqui, VAN: Vila Andrade, TRE: Tremembé, MOR: Morumbi, CAC: Cachoeirinha, TUC: Tucuruvi, MOE: Moema, PIN: Pinheiros, SAN: Santana, JPA: Jardim Paulista, CON: Consolação, PER: Perdizes, CBE: Campo Belo, JAB: Jabaquara, IBI: Itaim Bibi, SAM: Santo Amaro, SAL: Saúde, BFU: Barra Funda, LIB: Liberdade, VMA: Vila Mariana, CVE: Casa Verde, BRE: Bom Retiro, BVI: Bela Vista, PAR: Pari, JAC: Jaçanã, LIM: Limão, VME: Vila Medeiros, SCE: Santa Cecília, VGU: Vila Guilherme, SE: Sé, CAM: Cambuci, REP: República, BRS: Brás, API: Alto de Pinheiros, LAP: Lapa, FRE: Freguesia do Ó, BEL: Belém, MOO: Mooca. 
A área de estudo possui poucas regiões com declividade acentuada. Estas concentram-se no extremo norte da área de estudo, na região da Serra da Cantareira, apresentando-se vegetadas. Portanto a classe de prioridade "muito alta" é pouco representativa na região. A declividade deste local resultou na prioridade média para arborização em alguns pontos, apesar do seu elevado índice de vegetação. Podemos notar que os pontos em vermelho (prioridade alta para arborização) correspondem às manchas não vegetadas da região (figura 2).

É possível visualizar no mapa grandes manchas da classe de prioridade "alta" e "média-alta" para arborização urbana, concentradas nas regiões centro-norte, nos distritos: Cachoeirinha, Freguesia do Ó, Mandaqui, Tucuruvi, Limão, Casa Verde, Santana, Vila Guilherme e Jaçanã; e centro-sul, nos distritos: Alto de Pinheiros, Perdizes, Consolação, Bela Vista, Liberdade, Vila Mariana e Sé. Essas manchas devem receber maior atenção quanto à implantação de espaços verdes, principalmente através da arborização viária.

Os distritos Mandaqui, Tucuruvi e Tremembé são razoavelmente arborizados, entretanto, a declividade dessa região é acentuada, o que resultou na prioridade média-alta para arborização. $O$ aumento de espaços vegetados é especialmente importante nessas regiões para a constituição de uma zona de amortecimento do Parque Estadual da Cantareira. Dessa forma, o contraste da cobertura do solo seria menor entre o parque e os bairros adjacentes, favorecendo os fluxos biológicos e de pessoas. Além disso, melhorar a oferta e a acessibilidade de áreas verdes, trazendo-as para o cotidiano da população local, auxilia na educação ambiental e na conservação das áreas protegidas, inclusive do Parque Estadual da Cantareira.

Esses espaços verdes poderão também conectar os fragmentos de vegetação da cidade. Dessa forma, além de reduzir os problemas ambientais já mencionados, podem aumentar a conectividade da paisagem.

Os bairros Mooca, Brás, Bom Retiro, Pari e Santa Cecília, localizados na região central, possuem baixo índice de vegetação (figura 2), entretanto, por apresentarem topografia mais plana, não se enquadram nas zonas de prioridade para arborização deste trabalho.

Cabe salientar, que não propomos neste estudo a conversão total de uso do solo dessas áreas em espaços vegetados. O mapa apresentado constitui uma ferramenta para auxiliar na tomadas de decisão e na elaboração de diretrizes específicas para o regramento do uso e ocupação do solo nestas porções do território. 
Podem ser utilizadas diferentes estratégias para o aumento de espaços verdes nas cidades, desde índices urbanísticos diferenciados e área mínima permeável, até incentivos fiscais aos proprietários para aumento da arborização e permeabilidade do solo... Oliveira (1996) apresenta quatro delas em estudo realizado no município de São Carlos, SP. A primeira estratégia seria o aumento da arborização de vias, em que o autor apresenta, inclusive, soluções para amenização dos conflitos estre as estruturas urbanas e a vegetação. A segunda estratégia visa a conversão de áreas verdes inacessíveis para a população (devido à falta de infraestrutura) em praças e parques, por meio da eliminação de barreiras (muros, cercas e portões), planejamento de triIhas e pistas para caminhada. A terceira estratégia corresponde à integração de áreas devolutas e com uso não planejado ao sistema de espaços verdes, por meio do manejo das áreas para atendimento de diversas demandas do meio urbano. Finalmente, a quarta estratégia representa a recuperação de áreas degradadas ou residuais, que estão vazias ou abandonadas, sendo que muitas são áreas públicas que apresentam enorme potencial para conversão em uma área verde multifuncional, cumprindo funções recreativas, ecológicas, de drenagem e mobilidade (SANCHES, 2014).

\section{CONCLUSÕES}

Diferentemente da maioria das ações e políticas públicas que são voltadas ao fomento de espaços verdes em áreas inundáveis ou estabelecimento de infraestruturas que otimizam a drenagem, este trabalho propõe uma visão mais abrangente, enfrentando preventivamente os problemas de escoamento superficial à montante, onde é mais intenso.

O mapa de áreas prioritárias para arborização urbana indica as regiões que possuem menor índice de vegetação e maior declividade, e que, portanto, devem receber atenção do poder público para o aumento de espaços verdes, capazes de reduzir os problemas decorrentes da elevada velocidade de escoamento superficial da água da chuva, como alagamentos, erosão e deslizamentos de solo.

Nota-se que em diversos municípios brasileiros a distribuição dos espaços verdes é realizada de forma aleatória ou motivada por interesses particulares. Neste contexto, devem ser propostos novos modelos de planejamento que concilie a manutenção da integridade ambiental e as necessidades da população.

A combinação dos critérios abordados, visando a diminuição do escoamento superfi- 
cial, mostrou ser eficiente para a determinação das áreas prioritárias para arborização urbana. O método utilizado apresenta soluções simples e de baixo custo, essas características, associadas às vantagens de uso de Sistemas de Informações Geográficas constituem uma ferramenta importante para tomada de decisão e desenvolvimento de diretrizes assertivas no planejamento urbano.

\section{AGRADECIMENTOS}

Agradecemos à Fundação Capes pela concessão de bolsas e à Fundação DigitalGlobe pela doação de imagens de satélite de alta resolução.

\section{REFERÊNCIAS}

ALVES, P.L. Capacidade de interceptação pelas árvores e suas influências no escoamento superficial urbano. 2015. 100p.Tese (Doutorado). Universidade Federal de Goiás, Programa de Pós Graduação em Ciências Ambientais. 2015

BARGOS, D. C.; MATIAS, L. F. Mapeamento e análise de áreas verdes urbanas em Paulínia (SP): estudo com a aplicação de geotecnologias. Soc. \& Nat., Uberlândia, ano 24 n. 1, 143-156, 2012.

Brasil. Presidência da República. Parcelamento do solo urbano. Lei 6.766/79. Brasília, DF: Série Documentos Sociais, 1980.

COSTA, J. A. Uso de imagens de alta resolução para definição de corredores verdes na cidade de São Paulo. 2010. 114p. Dissertação (Mestrado em Recursos Florestais) - Escola Superior de Agricultura "Luiz de Queiroz Universidade de São Paulo, Piracicaba. 2010.

DUARTE, D. H. S; SERRA, G. G. Padrões de ocupação do solo e microclimas urbanos na região de clima tropical continental brasileira: correlações e proposta de um indicador. Ambiente Construído, v. 3, n. 2, p. 7-20, 2003.

FORMAN, R.T.T., GORDON, M. Landscape Ecology. John Wiley \& Sons, New York. 1986. 
HIJIOKA, Akemi. et. Al. Espaços livres e espacialidades da esfera pública: Uma proposição conceitual para o estudo de sistemas de espaços livres urbanos no país. Paisagem Ambiente: ensaios. n. 23, São Paulo, 2007, p. 116 - 123.

IBGE. Instituto Brasileiro de Geografia e Estatística. 2010. Disponível em: http://cidades.ibge.gov.br/xtras/perfil.php?codmun=355030. Acesso em: 06. set. 2016.

JACOBI, P. Cidade e meio ambiente: percepções e práticas em São Paulo. $2^{\mathrm{a}}$ ed., Annablume, 2006, 206p.

JESUS, S. C., BRAGA, R. Análise espacial das áreas verdes urbanas da Estância de Águas de São Pedro - SP. Revista Caminhos de Geografia, v. 18, n. 16, p. 207224, 2005. ISSN 1678-6343.

MAGALHÃES. Análise dos espaços verdes remanescentes na mancha urbana conurbada de Belo Horizonte - MG apoiada por métricas de paisagem. 2013. 163p. Dissertação (Mestrado). Universidade Federal de Minas Gerais, Belo Horizonte. 2013.

OLIVEIRA, C. H. Planejamento ambiental na Cidade de São Carlos (SP) com ênfase nas áreas públicas e áreas verdes: diagnóstico e propostas. 1996. 181p. Dissertação (Mestrado). Universidade Federal de São Carlos, São Carlos. 1996.

SANCHES, P.M. De áreas degradadas a espaços vegetados. São Paulo: Ed. Senac, 2014.

SILVA FILHO, D. F. Aplicação de videogeografia aérea multiespectral na avaliação de floresta urbana. 2004. 88p. Tese (Doutorado em Agronomia) - Faculdade de Ciências Agrárias e Veterinárias, Universidade Estadual Paulista "Júlio de Mesquita Filho", Jaboticabal. 2004.

SILVA, L.F.; LIMA, A.M.L.P; SILVA FILHO, D.F.; COUTO, H.T.Z. Capacidade de interceptação pelas árvores e suas influências no escoamento superficial urbano. REVSBAU, Piracicaba - SP, v.4, n.3, p.32 - 48, 2009.

TORRES, E. M. Metodologia para macroplanejamento de áreas verdes urbanas. 2003. 68p. Dissertação (Mestrado em Ciência Florestal), Universidade Federal de Viçosa, Viçosa. 2003. 